\title{
Marin B., Regnard C. (dir.), POLICE ! Les Marseillais et les forces de l'ordre dans l'histoire
}

Marseille, Éditions Gaussen-Le Cardinal, 2019, 143 p., in-4, ISBN

978-2-356981-78-3

\section{René Lévy}

\section{(2) OpenEdition}

\section{Journals}

Édition électronique

URL : https://journals.openedition.org/chs/2722

DOI : $10.4000 /$ chs. 2722

ISSN : 1663-4837

Éditeur

Librairie Droz

\section{Édition imprimée}

Date de publication : 30 octobre 2020

Pagination : 143-143

ISSN : 1422-0857

Référence électronique

René Lévy, "Marin B., Regnard C. (dir.), POLICE! Les Marseillais et les forces de l'ordre dans I'histoire », Crime, Histoire \& Sociétés / Crime, History \& Societies [En ligne], vol. 24, $n^{\circ} 1 \mid$ 2020, mis en ligne le 18 novembre 2020, consulté le 10 novembre 2022. URL : http://journals.openedition.org/chs/2722 ; DOI : https://doi.org/10.4000/chs.2722

Ce document a été généré automatiquement le 10 novembre 2022.

Tous droits réservés 


\title{
Marin B., Regnard C. (dir.), POLICE ! Les Marseillais et les forces de l'ordre dans l'histoire
}

\author{
Marseille, Éditions Gaussen-Le Cardinal, 2019, 143 p., in-4, ISBN \\ 978-2-356981-78-3
}

\section{René Lévy}

\section{RÉFÉRENCE}

Marin B., Regnard C. (dir.), POLICE ! Les Marseillais et les forces de l'ordre dans l'histoire, Marseille, Éditions Gaussen-Le Cardinal, 2019, 143 p., in-4, ISBN 978-2-356981-78-3.

1 Si l'historiographie de la police française a beaucoup progressé dans les dernières décennies, on compte relativement peu d'études sur les polices des grandes villes. C'est particulièrement le cas de Marseille, la deuxième ville française, et c'est pourquoi on peut saluer la parution de cet ouvrage qui constitue une introduction intéressante à cette histoire depuis l'Ancien Régime.

2 Sous la direction de Brigitte Marin et Céline Regnard, cet ouvrage a été conçu pour accompagner et prolonger une exposition aux Archives de Marseille, en parallèle de celle que Vincent Denis, Isabelle Foucher et Vincent Milliot ont conçu sur « La police des Lumières » aux Archives nationales à Paris. L'ouvrage vise principalement le grand public, mais les spécialistes y trouveront également quantité d'aperçus et de pistes pour des recherches futures.

Une petite trentaine de notices, rédigées par une quinzaine de spécialistes, enrichies d'une belle iconographie et complétées de nombreuses cartes inédites, d'une bibliographie et d'un glossaire balayent l'histoire policière de la ville en multipliant les angles d'approche : les grandes étapes de l'histoire institutionnelle (Ancien Régime, étatisation de 1908, Deuxième guerre et Libération, recréation d'une police municipale en 1974) ; l'évolution de l'organisation locale (découpage urbain, implantations 
policières, évolution des corps de police, tribunal de police) ; les attentes des autorités et du public envers les policiers ; les cibles du contrôle policier (police des étrangers, des jeux, de la prostitution). Les principales fonctions policières sont évoquées : police sanitaire (la peste de 1720), sécurité (l'éclairage public), maintien de l'ordre, police criminelle. L'ouvrage s'achève sur une évocation du "polar marseillais », qui a connu un essor particulier à partir des années 1990, et dont les thèmes reflètent les évolutions sociales et politiques de la ville.

4 Même si l'on peut regretter que l'ordonnancement des chapitres ne fournisse pas un véritable fil conducteur à la lecture, entremêlant sans logique apparente les sujets et les périodes, le lecteur attentif pourra repérer certains grands thèmes parcourant l'ensemble et avant tout les particularités liées au caractère portuaire de la ville, avec ce qu'il implique de circulations humaines et matérielles, de trafics en tous genres et de risque sanitaire. On retiendra également les vicissitudes de la professionnalisation policière, de la conception du bon policier sous l'Ancien Régime aux espérances déçues de l'étatisation ; ou, plus en filigrane, les tensions entre les autorités locales et l'État dans une ville que son ouverture sur le monde rend peut-être plus rétive que d'autres au pouvoir parisien.

\section{AUTEURS}

\section{RENÉ LÉVY}

CESDIP

rlevy[at]cesdip.fr 